Document downloaded from:

http://hdl.handle.net/10251/100715

This paper must be cited as:

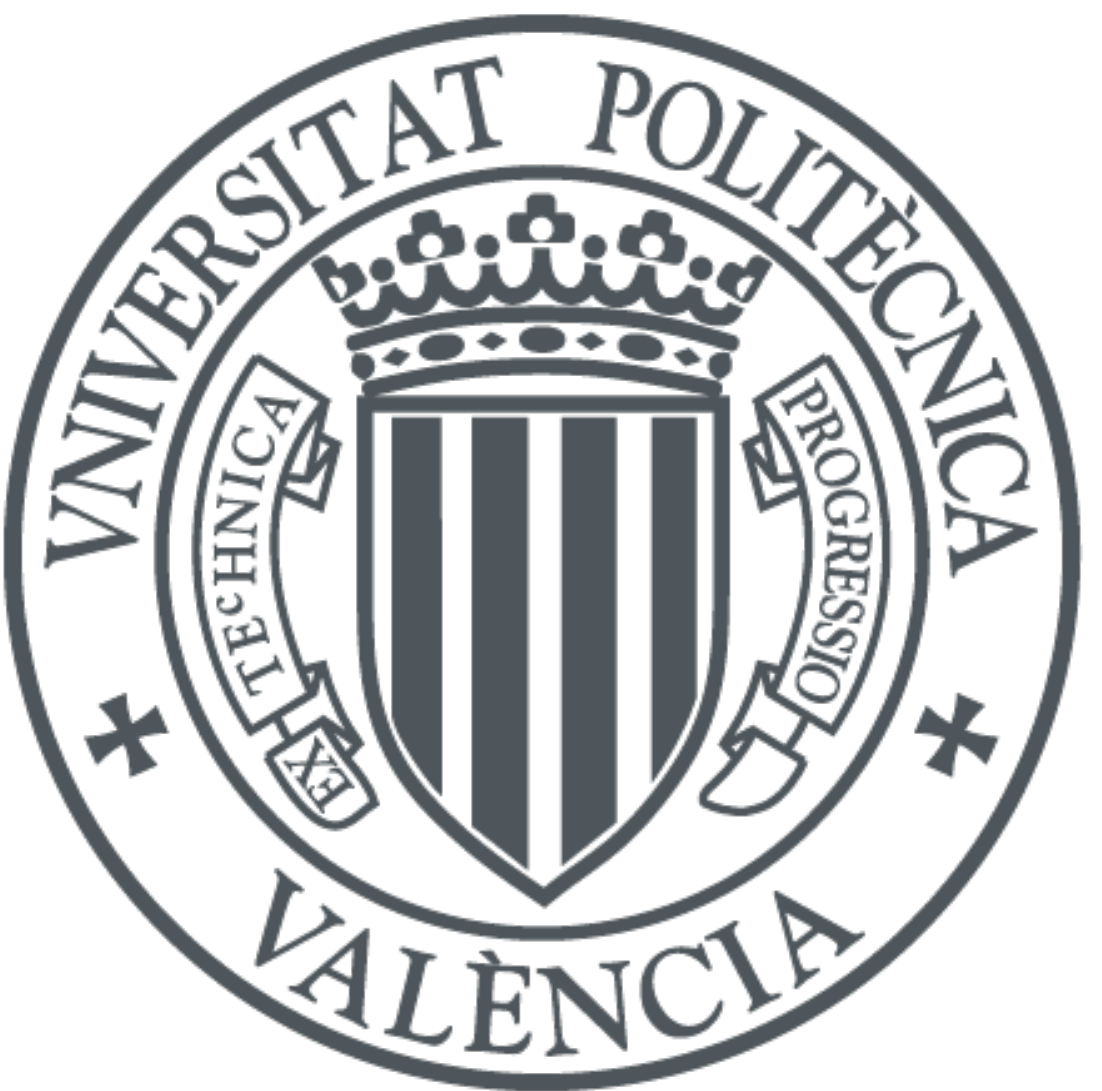

The final publication is available at

https://doi.org/10.1504/IJSTM.2016.078539

Copyright Inderscience Enterprises Ltd.

Additional Information 


\title{
ABC Classification of Spare Parts considering Costs and Service
}

\author{
Manuel Cardós ${ }^{1}$, Ester Guijarro, Eugenia Babiloni
}

\begin{abstract}
This paper focuses on the multi-item problem where it is necessary to reach an overall stock availability of the spare parts while minimizing involved costs. Over the last years a number of authors have proposed a variety of approaches and provided different rules in order to classify items in ABC classes. An additional optimization has to be performed in order to minimize the inventory cost while fulfilling a target service level. The proposed approach focuses on the characteristics of spare parts and optimizes the inventory cost subject to the overall target fill rate by means of a closed form formula for calculating the fill rate of every item independently. This new method is validated with a dataset of spare parts of an airline company and clearly outperforms the alternative methods in terms of inventory cost reduction and ease of calculation. Extensions of our results are also indicated.
\end{abstract}

Keywords-spare parts; ABC classification; fill rate; multi-item environment; exponential demand

\section{INTRODUCTION}

Spare parts inventory management has a high impact on the economic performance of a company, for example in the process industry or the airline industry where large installations provide the goods or service required by the customers. Obviously, spare parts inventory management is not responsible for the failure rate of the installation or its components, but the availability of an item may shorten the downtime. Given the high cost of every hour an installation is unavailable, the spare parts should be readily available and therefore its stock tends to increase. It is very common to stablish as a constraint a lower bound of the fill rate, i.e., the fraction of the spare parts units needed that are immediately available from stock. However, the involved stock costs should be as low as possible in order to remain competitive by means of low production costs or high client service or both.

Previous explanation deals to a typical stock policy but the real situation is more complex given that hundreds or even thousands of items are managed in a typical spare parts warehouse. Therefore this multi-item problem can be expressed as minimizing the inventory costs of all the items subject to an overall fill rate. This trade-off between the overall service level and the total

\footnotetext{
${ }^{1}$ Universitat Politècnica de València. Camino de Vera s/n, Valencia, Spain. E-mail: mcardos@doe.upv.es
} 
inventory cost involved may become critical from an economic perspective not only for the management of service spare parts but also for the management of the spare parts needed by an industrial company.

The main objectives of this paper are: (a) modeling this problem accordingly to the way managers have to make decisions so that the usual stockout cost is replaced by a service level target to be fulfilled; (b) determining the optimum of this model and a procedure to apply it, if necessary; (c) determining the ranking criterion according to this model in order to obtain $A B C$ classes; and (d) numerical validation of the proposed method including its performance when compared to alternative approaches.

Therefore, the main contribution is a new approach that reduces significantly inventory costs and assures a target overall service.

The remainder of this paper is organized as follows. In Section II we present the stock policy and notation used in this paper. In Section III and IV we present previous research in this topic, including the existing estimation methods and some comments on its suitability for spare parts. Section V includes the model we propose and the derivation of the resulting closed formula. An empirical validation is shown in section VI based on a real dataset including the performance of the existing and proposed method. Finally in Section VII we provide our conclusions and possible extensions.

\section{Stock Policy AND Notation}

This paper is focused on continuous review policy and spare parts. In this inventory policy the stock of an item is reviewed at every time instant and a replenishment order of a predetermined size $Q$ is released when the stock lowers to a predefined level s, named reorder point (see Fig. 1).

We focus on a continuous review stock policy subject to: (a) backlog is allowed, so when an order cannot be fulfilled it just waits until the necessary stock is again available; (b) the demand in a time period is fulfilled with the stock at the end of previous period; and (c) the demand is assumed to be exponential and stationary during the lead time. Note that demand of an item is exponential when its failure rate is constant, so some authors have modeled the spare parts demand with an exponential distribution [1].

The notation used in this paper is:

A ordering cost,

$r \quad$ cost of holding $1 €$ stock value during a unit time,

$v \quad$ unit cost,

$h \quad$ holding cost $(h=r v)$, 
SS safety stock,

$s \quad$ reorder point,

Q reorder quantity,

D demand per unit time,

DT total demand per unit time, i.e., including the demand of every item

$L \quad$ lead time,

U immediately served units,

$f_{L}($.$) \quad probability distribution of demand in the lead time,$

$F_{L}($.$) \quad cumulative distribution of demand in the lead time,$

FR fill rate, i.e., the expected fraction of the demand being fulfilled immediately from the shelves,

$F R_{\text {overall }}$ overall fill rate, i.e., the fraction of all demanded units that can be served,

$F R_{\text {target }}$ overall fill rate target,

CSL cycle service level, i.e., the fraction of cycles ending without stock,

$p \quad$ demand weight, i.e., fraction of an item demand related to the total demand, measured in units,

$N \quad$ number of existing items.

In the rest of this paper, sub-indexes are used to denote a particular item.

\section{LITERATURE REVIEW}

Probably due to its economic impact, the classification of items has drawn much attention in recent years ([2], [3]) and also the classification and management of spare parts ([4], [5]). However, the consideration of a target service level is usually replaced by an stockout cost so it is convenient to review these alternative approaches.

The overall fill rate target can be obtained aggregating individual item targets weighted with the demand fraction corresponding to each item [6] because:

$$
F R_{\text {overall }}=\frac{1}{D T} \sum_{i=1}^{N} U_{i}=\sum_{i=1}^{N} \frac{U_{i}}{D_{i}} \frac{D_{i}}{D T}=\sum_{i=1}^{N} p_{i} F R_{i}
$$


Probably the most usual and straightforward approach is to choose the same target for every item, so equation (1) holds independently of the demand weight of every item. Unfortunately this simple approach leads to high inventory costs, as will be seen later.

Another approach is based on classifying items into ABC classes and defining the same fill rate target for the items according to the ABC class they belong to [7]. However, authors maintain different positions on the way it should be done. For example, [8] argue that class A items deserve the highest targets in order to avoid frequent unmet demand as they usually provide most of the profit. On the contrary [9] point out that class $\mathrm{C}$ items should have the highest targets in order to avoid numerous stockouts and their related replenishment orders.

Other authors are more focused on inventory theory, specifically on inventory costs and service. For example [10] minimize ordering and holding costs subject to a global target cycle service and a given frequency of replenishments being demand normally distributed. As a result, they propose an $\mathrm{ABC}$ ranking rule based on the unit holding cost, the lead time and the expected annual demand.

Based on minimizing penalty and holding costs, [11] resulting in a ranking index based on the unit holding cost, the penalty cost and the order size.

This approach has an important drawback: it is assumed that penalty costs are known nevertheless the evidence that it is not possible to be estimated. In the search of a feasible estimation method, several alternatives have been proposed: letting the manager to determine subjectively the penalty costs [12], solving another problem where penalty costs are replaced with a service constraint so that the shadow price of that constraint results into the estimation of the penalty cost [13] or even using fuzzy logic to determine the optimum policy [14]. None of these approaches have proved to be convenient in practice, so estimating hundreds or thousands of penalty costs is clearly unfeasible. Moreover, [15] argue make many people to abandon this inventory cost because of the difficulties to estimate penalty costs and use a service constraint instead. Moreover, other authors [16] point out that penalty cost estimation is virtually impossible, so the most usual approach is using service level constraints.

In spite of [10] and [11] have improved ranking rules, both of them need iterative computation for assigning a target service level to each item. This paper proposes a closed form formula to determine the fill rate for every item that minimizes holding and ordering costs while reaching a global target fill rate. So, the method proposed in this paper can be applied without any numerical optimization. 


\section{EXISTING ESTIMATION Methods}

\section{A. One Fill Rate criterion}

Probably the most straightforward and simple approach is to set up the item fill rates with the overall target. This can be expressed as

$$
F R_{i}=F R_{\text {target }} \quad i=1, \ldots, N
$$

Being the demand exponentially distributed during the lead time $L_{i}$ for every item $i=1, \ldots, N$ with an average demand $D_{i}$ per period time, the expected units of that item that are not served during a cycle are

$$
\operatorname{UNSC}_{i}=\int_{s_{i}}^{\infty}\left(x-s_{i}\right) f_{L}(x) d x=D_{i} L_{i} \exp \left(-\frac{s_{i}}{D_{i} L_{i}}\right)
$$

and the fill rate for a given item is

$$
F R_{i}=1-\frac{U N S C_{i}}{D_{i} L_{i}}=1-\exp \left(-\frac{S_{i}}{D_{i} L_{i}}\right)=1-\exp \left(-\frac{S S_{i}-D_{i} L_{i}}{D_{i} L_{i}}\right)=F_{L_{i}}\left(S S_{i}-D_{i} L_{i}\right)
$$

Obviously this approach assures that the overall target is met although involved costs are not considered. In fact, as we will see later, this approach leads to the highest cost. Therefore we will use this approach as a reference in order to assess the efficiency of other methods.

\section{B. Volume Classes criterion}

This approach recognizes that different items may need different fill rates and classifies the item according to its demanded units. So, the contribution of every item to the overall target is weighted with the fraction of the total demand it represent and the procedure is:

1. Arrange the items in descending $p_{i}$.

2. Classify the items into classes; every item has the fill rate of the class it belongs to.

3. Determine class fill rates subject to the overall target fill rate. Optional: determine class fill rates that minimize overall costs.

The overall cost function includes holding and ordering costs

$$
\min \sum_{i=1}^{N}\left(h_{i} S S_{i}+h_{i} \frac{Q_{i}}{2}+A_{i} \frac{D_{i}}{Q_{i}}\right)
$$

The overall fill rate can be computed based on equation (1) 


$$
\sum_{i=1}^{N} p_{i} F R_{i}=F R_{\text {target }}
$$

As long as the order quantity is usually predetermined, the objective function (5) can be simplified because the holding costs and the ordering costs are constant for every item

$$
\min \sum_{i=1}^{N} h_{i} S S_{i}
$$

This reasoning applies to all the methods in this document. Note that optimization (step 3) is optional and is usually replaced by assigning the highest fill rate target to A class, a lower one for $B$ class and so on.

\section{Zhang et al. ranking criterion}

This is the first approach focused on minimizing costs. As explained below, [10] minimizes holding and ordering costs subject to a target overall cycle service and a given order frequency, assuming that demand is normally distributed. This method provides a ranking rule and a procedure:

1. Arrange the items in descending order of $\mathrm{D}_{\mathrm{i}} /\left(\mathrm{L}_{\mathrm{i}} \mathrm{h}_{\mathrm{i}}{ }^{2}\right)$.

2. Classify items into classes; all the items in a class have the same fill rate.

3. Determine class fill rates that minimize overall costs subject to the overall target fill rate.

The most important purpose of a spare parts inventory is to reach a high availability of an installation with the lowest inventory cost. So the main drawbacks of this approach are: (a) it is more realistic to measure the service as the fill rate instead of the cycle service level; (b) the main consequence of limiting the order frequency is a cost increase; and (c) demand of spare parts is not usually normally distributed.

\section{Teunter et al. ranking criterion}

Another method is focused on minimizing costs without any service constraint because [11] propose a cost function including penalty and holding costs assuming that demand is normally distributed. As a result, minimum cost is characterized by

$$
C S L_{i}=1-\frac{h_{i} Q_{i}}{b_{i} D_{i}} \quad i=1, \ldots, N
$$

The resulting ranking rule and a procedure are:

1. Arrange the items in descending order of $\left(b_{i} D_{i}\right) /\left(h_{i} Q_{i}\right)$. 
2. Classify the items into classes; all the items in a class have the same cycle service.

3. Determine class cycle service rates that minimize overall costs subject to the overall target fill rate.

The first drawback of this approach is that ordering costs are not considered, so cost calculation is incomplete. But the most important objection is the use of penalty costs given the limitations explained in Section III. As authors probably do, we assume that penalty costs are the same for all the items as long as this assumption may not alter the ranking rule.

\section{Proposed Method}

\section{A. Model formulation}

We minimize ordering and holding costs because these costs not only represent the inventory costs that take place but are also appropriate and measurable. Instead of using penalty costs, we choose the fill rate as service metric constraint because it is the one that better represents the availability of an installation from a managerial point of view. Therefore we formulate the model as optimizing the inventory cost of the safety stocks as expressed by (7) subject to the overall service constraint expressed by (6) and whose item fill rates can be computed by (4) given that demand is exponentially distributed. So, this approach can be seen as choosing the safety stock $S S_{i}$ for every item so that the overall service constraint is reached at the minimum cost.

\section{B. Proposed method}

This optimization can be solved using Lagrange multipliers being the Lagrange function

$$
\min \Lambda=\sum_{i=1}^{N} h_{i} S S_{i}-\lambda\left[\sum_{i=1}^{N} p_{i} F R_{i}-F R_{\text {target }}\right]
$$

The minimum of this function is simultaneously characterized by equations (6) and (10)

$$
h_{i}=\lambda \frac{\partial F R_{i}}{\partial S S_{i}} \quad i=1, \ldots, N
$$

After some algebra, the fill rate for every item is obtained

$$
F R_{i}=1-\frac{1-F R_{\text {target }}}{\sum_{i=1}^{N} h_{i} D_{i} L_{i}} \frac{h_{i} D_{i} L_{i}}{p_{i}}
$$


Equation (11) is a closed form formula, so it is straightforward to obtain optimal fill rates even for a large number of items. Note that this approach not only provide a ranking criterion as previous methods do but also a procedure for estimating fill rates for every item.

\section{Proposed ranking criterion}

As previously explained, this method can be used to determine individual fill rates applying equation (11) providing the best cost performance. However, when needed it can also be used for item classification purposes using the next ranking rule and procedure:

1. Arrange the items in descending order of $\mathrm{p}_{\mathrm{i}} /\left(\mathrm{h}_{\mathrm{i}} \mathrm{D}_{\mathrm{i}} \mathrm{L}_{\mathrm{i}}\right)$.

2. Classify items into classes; all the items in a class have the same fill rate.

3. Determine class fill rates that minimize overall costs subject to the overall target fill rate.

\section{EMPIRICAL VALIDATION}

We consider a dataset of spare parts from a regional airline company and include daily demand data for a three years period. These data are described in Table I and show that: (a) most of the items have a unit order accordingly with a quite low daily demand; (b) although the lead times varies from 1 to 8 weeks for most of the items, some items exceed a year because of its technical complexity and the limited available sources; and (c) the cost of these items is quite high as a median of 8,765 €/unit show. Additionally, these 941 SKUs suppose an average expense of 295,000 €/year consumption of spare parts.

We use the same six classes A, B, C, D, E and F including 4\%, 6\%, 10\%, 15\%, 25\% and 40\% for all the methods we test. These methods are described in Section IV and Section V: (a) One fill rate criterion; (b) Volume classes criterion; (c) Zhang et al. ranking criterion; (d) Teunter et al. ranking criterion; and (e) proposed direct estimation (Proposed). For methods (b), (c) and (d) optimization is performed using Solver tool in Excel.

We have compared the performance of these procedures considering different overall target fill rates of $90 \%, 95 \%$ and $99 \%$. Performance is measured in terms of the safety stock cost they provide as long as the fill rate constraint is satisfied in every method. Obviously, safety stock increases with the target service level, so we compute the relative variation of the safety stock cost of every method when compared with the first one. The results are in Table II, Table III and Table IV for 90\%, 95\% and 99\% target fill rate respectively. These tables also include the average fill rate for the classes of every method.

Proposed method is the clear winner for all the cases This cost advantage is especially important in this context where inventory costs are so high, e.g., cost reduction for a 99\% target fill rate is about 1.7 millions of euros when compared to the second performer, Teunter et al. ranking criterion. Zhang et al. ranking criterion obtains similar results than Teunter el al. in the 
first case but just as the volume classes in the other cases. It seems that Volume classes and Zhang et al. criterion cannot be recommended.

The controversy on setting up the highest service level to class A or alternatively to class $\mathrm{F}$ in the Volume class method can be explained because there is not a clear pattern. Although in these cases the higher fill rates are usually assigned to A classes, in Table III the fill rate of classes D, $\mathrm{E}$ and $\mathrm{F}$ are ascending and higher than class $\mathrm{C}$. This can also be seen as a clear sign of the inadequacy of this criterion. The same reasoning applies to Zhang et al. ranking criterion and Teunter et al. ranking criterion as seen in Table II and Tables II and IV respectively.

Finally, the lowest safety stock cost in these three cases is always higher than the annual spare parts consumption. It is not surprising because of the low demand of most of the items and its high unit cost. Therefore, the target of high availability of the installation is usually obtained with a high investment on inventory and a complex and expensive management in order to assure a high availability of the spare parts.

\section{CONCLUSIONS}

From a managerial point of view, usually the starting point of spare parts inventory systems is establishing an overall target of item availability. Several methods have been previously proposed and reviewed in this Section III and IV.

Based on the characteristics of spare parts, we propose a new method that clearly outperforms the previous ones when checked with a real dataset. This new method not only provides a significant reduction in safety stock costs when compared with the results of the previous methods but also it is easy to be applied given that the proposed method uses a closed form formula that reduces significantly the computational effort.

We have also found some signs of inadequacy of the Volume class, Zhang et al. and Teunter et al. methods.

Future research may focus on extending these results to other business situations by means of considering other demand distribution functions but maintaining the usual managerial point of view of reaching an overall target service with the minimum inventory costs.

\section{REFERENCES}

[1] J.K. Cochran and T.P. Lewis, "Computing small-fleet aircraft availabilities including redundancy and spares," Computers \& Operations Research, vol. 29, no. 5, pp. 529-540, Apr.2002.

[2] T.J. van Kampen, R. Akkerman, and D.P. van Donk, "SKU classification: a literature review and conceptual framework", International Journal of Operations \& Production Management, Vol. 32 Iss 7 pp. 850 - 876, 2012. 
[3] M.Z. Babai, T. Ladhari, and I. Lajili, "On the inventory performance of multi-criteria classification methods: empirical investigation”, International Journal of Production Research, 53:1, 279-290, 2015.

[4] I. Roda, M. Macchi, L. Fumagalli, P. Viveros, "A review of multi-criteria classification of spare parts: From literature analysis to industrial evidences", Journal of Manufacturing Technology Management, Vol. 25 Iss 4 pp. 528-549, 2014.

[5] A. Molenaers, H. Baets, L. Pintelon, and G. Waeyenbergh, “Criticality classification of spare parts: A case study”, Int. J. Production Economics, 140, 570-578, 2012.

[6] U.W. Thonemann, A.O. Brown, and W.H. Hausman, "Easy quantification of improved spare parts inventory policies," Management Science, vol. 48, no. 9, pp. 1213-1225, 2002.

[7] E.A. Silver, D.F. Pyke, and R. Peterson, Inventory Management and Production Planning and Scheduling, Third Edition ed John Wiley \& Sons, 1998, pp. 74-145.

[8] D.J. Armstrong, "Sharpening Inventory Management," Harvard Business Review, vol. 63, no. 6, p. 42\&, 1985.

[9] E. Knod and R. Schonberger, Operations Management: Meeting Customer Demands., 7th ed ed. New York: McGraw-Hill, 2001.

[10] R.Q. Zhang, W.J. Hopp, and C. Supatgiat, "Spreadsheet implementable inventory control for a distribution center," Journal of Heuristics, vol. 7, no. 2, pp. 185-203, 2001.

[11] R. H. Teunter, M.Z. Babai, and A.A. Syntetos, "ABC Classification: Service Levels and Inventory Costs," Production and Operations Management, vol. 19, no. 3, pp. 343-352, 2010.

[12] R.D. Badinelli, "Optimal Safety-Stock Investment Through Subjective Evaluation of Stockout Costs," Decision Sciences, vol. 17, no. 3, pp. 312-328, 1986.

[13] K. Aardal, O. Jonsson, and H. Jonsson, "Optimal Inventory Policies with Service-Level Constraints," Journal of the Operational Research Society, vol. 40, no. 1, pp. 65-73, Jan.1989.

[14] T. Vijayan and M. Kumaran, "Inventory models with a mixture of backorders and lost sales under fuzzy cost," European Journal of Operational Research, vol. 189, no. 1, pp. 105-119, Aug.2008.

[15] P. Zipkin, Foundations of inventory management McGraw-Hill Higher Education, 2000.

[16] D.W. Fogarthy, J.H. Blackstone, and T.R. Hoffmann, Production and Inventory Management, Second ed South-Western Publishing Co., 1991. 


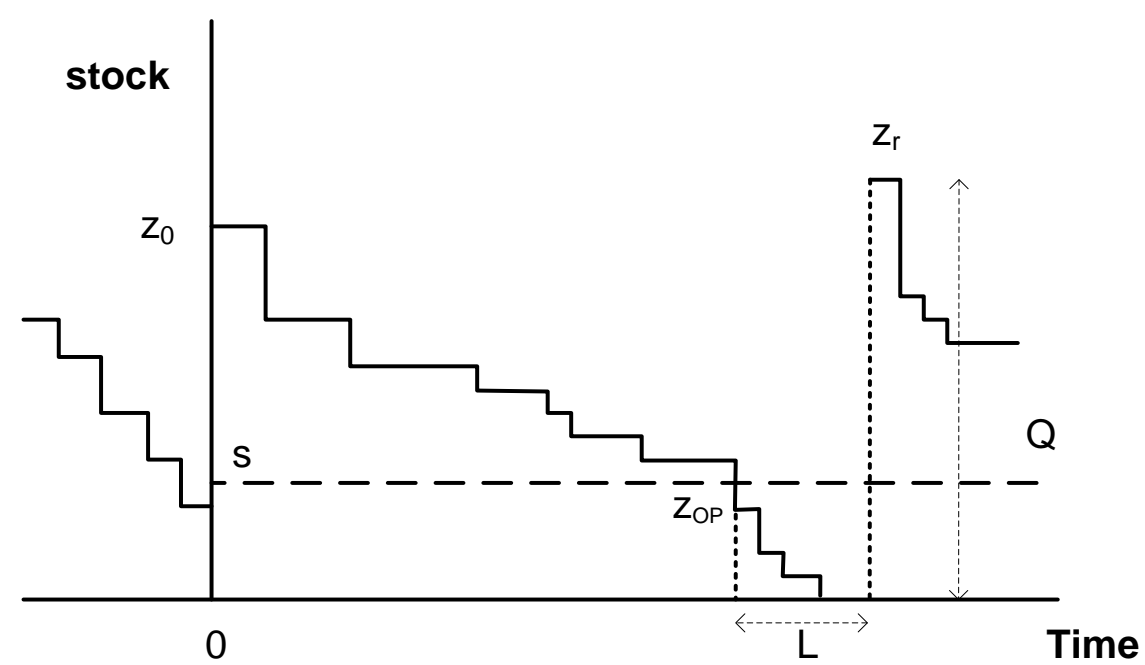

FIGURE 1. EXAMPLE OF THE STOCK EVOLUTION IN A CONTINUOUS REVIEW POLICY 
TABLE I. DESCRIPTIVE StATISTICS FOR THE DATASET (941 SKUs, HOLDING COST 0.25 YEAR $^{-1}$ )

\begin{tabular}{|r|r|r|r|r|r|}
\hline $\begin{array}{r}\text { Descriptive } \\
\text { statistic }\end{array}$ & $\begin{array}{r}\mathbf{Q} \\
\text { (units) }\end{array}$ & $\mathbf{p}$ & $\begin{array}{r}\mathbf{D} \\
\text { (units/day) }\end{array}$ & $\begin{array}{r}\mathbf{L} \\
\text { (days) }\end{array}$ & $\begin{array}{r}\mathbf{v} \\
\text { (€/unit) }\end{array}$ \\
\hline Minimum & 1 & 0,00004 & 0,001 & 7 & 23 \\
\hline 25 th quartile & 1 & 0,00004 & 0,001 & 29 & 3,033 \\
\hline Median & 1 & 0,00017 & 0,004 & 45 & 8,765 \\
\hline 75 th quartile & 1 & 0,00046 & 0,012 & 48 & 15,235 \\
\hline Maximun & 19 & 0,22567 & 5,955 & 445 & 475,881 \\
\hline
\end{tabular}




\begin{tabular}{|r|r|r|r|r|r|}
\hline Classes & One FR & $\begin{array}{r}\text { Volume } \\
\text { classes }\end{array}$ & $\begin{array}{r}\text { Zhang } \\
\text { et al. }\end{array}$ & $\begin{array}{r}\text { Teunter } \\
\text { et al. }\end{array}$ & Proposed \\
\hline $\mathrm{A}$ & 0,900 & 0,933 & 0,999 & 0,995 & 0,999 \\
\hline $\mathrm{B}$ & 0,900 & 0,827 & 0,880 & 0,898 & 0,991 \\
\hline $\mathrm{C}$ & 0,900 & 0,822 & 0,881 & 0,693 & 0,982 \\
\hline $\mathrm{D}$ & 0,900 & 0,817 & 0,860 & 0,796 & 0,965 \\
\hline $\mathrm{E}$ & 0,900 & 0,812 & 0,696 & 0,563 & 0,921 \\
\hline $\mathrm{F}$ & 0,900 & 0,806 & 0,368 & 0,381 & 0,627 \\
\hline Safety stock cost (000€) & 2.921 & 2.019 & 1.037 & 1.034 & 320 \\
\hline Cost variation (\%) & & $-31 \%$ & $-65 \%$ & $-65 \%$ & $-89 \%$ \\
\hline
\end{tabular}


TABLE III. SAFETY STOCK COST OBTAINED WITH DIFFERENT METHODS FOR 95\% TARGET FILL RATE

\begin{tabular}{|r|r|r|r|r|r|}
\hline Classes & One FR & $\begin{array}{r}\text { Volume } \\
\text { classes }\end{array}$ & $\begin{array}{r}\text { Zhang } \\
\text { et al. }\end{array}$ & $\begin{array}{r}\text { Teunter } \\
\text { et al. }\end{array}$ & Proposed \\
\hline $\mathrm{A}$ & 0,950 & 0,976 & 0,982 & 1,000 & 0,999 \\
\hline $\mathrm{B}$ & 0,950 & 0,899 & 0,902 & 0,962 & 0,996 \\
\hline $\mathrm{C}$ & 0,950 & 0,872 & 0,874 & 0,904 & 0,991 \\
\hline $\mathrm{D}$ & 0,950 & 0,888 & 0,890 & 0,829 & 0,982 \\
\hline $\mathrm{E}$ & 0,950 & 0,891 & 0,894 & 0,818 & 0,961 \\
\hline $\mathrm{F}$ & 0,950 & 0,901 & 0,903 & 0,638 & 0,785 \\
\hline Safety stock cost (000€) & 4.475 & 3.309 & 3.346 & 2.640 & 1.395 \\
\hline Cost variation (\%) & & $-26 \%$ & $-25 \%$ & $-41 \%$ & $-69 \%$ \\
\hline
\end{tabular}


TABLE IV. SAFETY STOCK COST OBTAINED WITH DIFFERENT METHODS FOR 99\% TARGET FILL RATE

\begin{tabular}{|r|r|r|r|r|r|}
\hline Classes & One FR & $\begin{array}{r}\text { Volume } \\
\text { classes }\end{array}$ & $\begin{array}{r}\text { Zhang } \\
\text { et al. }\end{array}$ & $\begin{array}{r}\text { Teunter } \\
\text { et al. }\end{array}$ & Proposed \\
\hline A & 0,990 & 0,992 & 0,993 & 1,000 & 1,000 \\
\hline $\mathrm{B}$ & 0,990 & 0,993 & 0,998 & 1,000 & 0,999 \\
\hline $\mathrm{C}$ & 0,990 & 0,990 & 0,952 & 0,978 & 0,998 \\
\hline $\mathrm{D}$ & 0,990 & 0,981 & 0,979 & 0,957 & 0,996 \\
\hline $\mathrm{E}$ & 0,990 & 0,971 & 0,994 & 0,965 & 0,992 \\
\hline $\mathrm{F}$ & 0,990 & 0,960 & 0,982 & 0,943 & 0,947 \\
\hline Safety stock cost (000€) & 8.084 & 7.543 & 7.456 & 6.184 & 4.486 \\
\hline Cost variation (\%) & & $-7 \%$ & $-8 \%$ & $-24 \%$ & $-45 \%$ \\
\hline
\end{tabular}

